\title{
A CONTRIBUIÇÃO DE ALAIN TOURAINE PARA O DEBATE SOBRE SUJEITO E DEMOCRACIA LATINO-AMERICANOS ${ }^{1}$
}

\author{
Carlos A. Gadea
}

\author{
Ilse Scherer-Warren
}

\begin{abstract}
RESUMO
O presente trabalho analisa diversas contribuições teóricas e analíticas do sociólogo francês Alain Touraine em relação às realidades políticas, sociais e culturais da América Latina. Partindo da idéia de que as principais preocupações desse autor fazem referência à dinâmica da modernidade latino-americana, procura-se compreender como esse tópico complementa-se com observações sobre a democracia e o sujeito social. O que interessa destacar é como, para Touraine, a modernidade latino-americana caracteriza-se a partir de uma inevitável tensão: a que se estabelece entre "universo instrumental" e "universo simbólico", correlato de uma imagem dual que continuamente se faz presente, a racionalização e a subjetivação. A partir disso, Touraine dedica-se a analisar a potencialidade política e social subjacente às idéias de "sujeito" e "ator social". Por fim, interessa aqui destacar as contribuições que se pode perceber nas concretas análises de movimentos sociais que hoje participam da heterogênea cena latino-americana, a saber, o movimento neozapatista de Chiapas, o Movimento dos Trabalhadores Rurais Sem-terra e, em um sentido mais genérico, os movimentos urbanos, ecológicos, negros, jovens, de mulheres e de educação intercultural.
\end{abstract}

PALAVRAS-CHAVE: Alain Touraine; modernidade latino-americana; sujeito social; movimentos sociais; democracia.

O sociólogo francês Alain Touraine deve ser dos poucos pensadores contemporâneos europeus que pensaram a democracia, a modernidade e os sujeitos sociais no contexto da América Latina. Acostumados a observar como europeus e norteamericanos não parecem muito preocupados em "pensar" esta região do planeta, pelo menos na área da pesquisa sobre movimentos sociais, o trabalho de Touraine apresenta-se altamente relevante e bastante instigante. A sua extensa obra demonstrou inquietações não meramente teóricas ou de caráter analítico, mas também uma evidente preocupação com as diferentes dinâmicas históricas e culturais das complexas sociedades latino-americanas nos seus diversos contextos históricos e geográficos. Pode-se considerar, sem dúvida, que houve e há muito a aprender-se sobre a América Latina, a partir do olhar e das reflexões analíticas desse sociólogo. Por isso, em uma tentativa de

\footnotetext{
1 Apresentado no XI Congresso Brasileiro de Sociologia, realizado em setembro de 2003 na Universidade Estadual de Campinas (Unicamp). Uma versão preliminar deste artigo foi publicado em Gadea e Scherer-Warren (2005).
}

esclarecer os diversos aportes de Alain Touraine para a Sociologia em geral e o debate político contemporâneo em particular, parece-nos oportuno considerar a originalidade interpretativa do autor para a análise da realidade latino-americana e, conseqüentemente, para a compreensão da dinâmica dos sujeitos pessoais e coletivos no nosso presente. Discutir a sua teoria poderia conduzir-nos a comparar a diversa gama de contribuições do autor com outros clássicos da Sociologia Política, combinar as suas reflexões com contemporâneos como Habermas ou Giddens ou talvez o contrastar com as teorias criticas e com os seus eventuais pontos de contato e discordâncias. Porém, o presente trabalho insere-se em uma discussão em que não se procura situar Touraine frente a pensadores e teóricos sociais contemporâneos particularizados, mas sim "re-situá-lo" em relação às contribuições teóricas e analíticas acerca da modernidade, da democracia, da política em geral e das mudanças culturais no heterogêneo contexto latino-americano.

Primeiramente, deve-se considerar que a diversidade de formas de como observar e analisar 
a modernidade latino-americana, sem dúvida parece corresponder-se com a própria diversidade ou heterogeneidade sócio-cultural que a caracteriza. Se isso parece óbvio, devemos reconhecer os difíceis impasses modernizadores que atravessaram as culturas latino-americanas, a difícil constituição de suas instituições políticas, jurídicas e econômicas, as "carências” muitas vezes marcadas como simples dados de uma futura modernidade que ainda está por chegar. Na complexa tarefa para apreender aqueles traços que possam ser definitivos desse processo histórico, têm-se estabelecido discussões que transitaram desde outorgar certa centralidade à perceptível "dependência econômica" e a uma defeituosa "modernização política" até chegar-se a uma preocupação acerca das dinâmicas de "integração social" sob a premissa da ampliação necessária dos processos de democratização política e social. O curioso tem sido que essas discussões negligenciaram, de uma forma ou outra, o caráter particular e específico de uma modernidade em tensão contínua, que se evidencia em um projeto elitista de racionalização (entenda-se aqui também disciplinamento, homogeneização e uniformidade) com uma dimensão sócio-cultural que manifesta o "dilaceramento" e a fragmentação próprios de intensos processos de subjetivação. Com isso, estabelece-se uma ambigüidade que caracteriza, de maneira profunda, a modernidade latino-americana.

Se aderirmos, primeiramente, aos postulados de Foucault, a racionalização leva-nos ao fortalecimento da lógica de integração social, do controle e, assim, de uma multiplicidade de lógicas de poder asfixiantes para o indivíduo. Não obstante, isso não representa o desaparecimento dos atores sociais, pois eles "están impacientes por afirmarse y lograr el reconocimiento de su libertad de sujetos", segundo afirma Alain Touraine (1997, p. 307). A partir de diversas experiências políticas e culturais da América Latina, Touraine confirmanos que a suposta experiência: "de la pérdida de identidad a la que nos resistimos dando tanta importancia a la autoestima, el auto desarrollo [...], nos impulsa en primer lugar a tratar, no de superar las contradicciones sociales, sino de aliviar el sufrimiento del individuo desgarrado, dado que éste no puede ya apelar a un dios creador, una naturaleza autoorganizada o una sociedad racional” (idem, p. 64).
Assim, Touraine assinala-nos uma modernidade latino-americana que, a partir dos seus particulares e diversos ritmos sócio-culturais, parece caracterizar-se por uma autêntica demanda de subjetivação, de afirmação e reconhecimento de aspectos culturais e de identidade pessoal e social. Em definitivo, o autor contribui para constatar uma grande característica dessa modernidade: sua contínua tensão entre um universo instrumental (sob os contornos racionalizadores da sociedade) e um universo simbólico (caracterizado pelas experiências de produção e afirmação dos sujeitos sociais). Os movimentos sociais estariam, dessa forma, dirigidos a aliviar essa tensão, assim como dirigidos para si mesmos e para o que se poderia denominar esforço de subjetivação: definido como um sujeito com vontade de ser reconhecido como ator. Como forma de sintetizar o que Touraine parece propor, pode-se afirmar que ele situa-nos frente a uma modernidade que não possui uma imagem única, senão duas: a racionalização e a subjetivação, dedicando-se a analisar a potencialidade política e social subjacente na idéia de sujeito e ator social.

Pode-se perceber que as principais contribuições analíticas do sociólogo Alain Touraine sobre a contemporaneidade na América Latina referemse, fundamentalmente, a três tópicos: a modernidade, a democracia e o sujeito social. Esses componentes têm sido tratados a partir de diferentes pontos de vista e temas concretos, durante toda a sua obra claramente dividida em três etapas: uma primeira, baseada, fundamentalmente, nos estudos empíricos realizados na América Latina, que se concentra na análise do trabalho e na consciência política dos trabalhadores, etapa marcada por uma especificidade dos ritmos urbanos da vida social. Uma segunda etapa caracteriza-se por um estudo concreto dos movimentos sociais dos anos 1960 e 1970, particularmente das rebeliões na França de 1968 e dos golpes de Estado latino-americanos. Por último, uma terceira etapa que em suas inquietações viaja desde a Sociologia até a Filosofia a partir do estudo da produção e do papel do sujeito dentro dos movimentos sociais.

Para compreender a dimensão dos estudos de Touraine no contexto latino-americano, lembrando especialmente seus trabalhos Crítica da modernidade (1994) e Poderemos viver juntos? 
Iguais e diferentes (1997), tem-se que se fazer referência àqueles debates que se situam em torno da questão do sujeito e da democracia. Assim, a dimensão que se relaciona com a particular modernidade latino-americana funciona como telão de fundo para esses debates centralizadores nas análises do dito autor. Isso significa que um diálogo parece estabelecer-se entre democracia e sujeito social, já que a ampliação de um é também a ampliação do outro. A idéia de democracia, para Touraine, não se materializa unicamente no conjunto de garantias institucionais e formais, mas sim representa a luta dos sujeitos, na sua cultura e sua liberdade, contra a lógica dominadora dos sistemas sociais. Nessa concepção, resulta importante que os sujeitos protejam sua memória e que possam combinar o pensamento racional, a liberdade pessoal e a identidade cultural. Dessa maneira, a democracia deve tratar de seguir dois caminhos: por um lado, criar espaços para a participação cada vez mais perceptíveis e, por outro lado, garantir o respeito às diferenças individuais e ao pluralismo.

Essas idéias parecem ser conseqüência de um diagnóstico particular sobre as condições atuais da América Latina, que se diferencia notoriamente daquelas condições “objetivas” para a mobilização política e social típicas dos anos 1960 e 1970. Não aconteceu, segundo o próprio Touraine manifesta, uma ruptura revolucionária sob aquelas condições, visto que hoje se conhecem atores sociais limitados mais do que forças revolucionárias globais. Esta necessária mudança da análise sugere que a formação de movimentos sociais depende menos de situações e condições "objetivas" do que de elementos formadores de atores definidos ao mesmo tempo por um determinado conflito social e por uma vontade de participação social, assim como conseqüência das relações entre demandas e exigências sociais e o sistema político. Assim, para Touraine, o sujeito social a analisar na América Latina é o movimento social, já que o conceito de classe social apresenta-se com escassa verificação empírica e de pouca utilidade para compreender as lutas atuais no espaço político e social. Segundo parece, o que se sugere é um marco de análise que navegue a partir da combinação entre movimento social e as questões próprias da diversidade cultural, entre mobilização e identidade pessoal e social.
A partir de tais postulados é possível, por exemplo, observar o surgimento, as identidades e as estratégias do movimento neozapatista do México, mais conhecido como Exército Zapatista de Libertação Nacional (EZLN), surgido publicamente nas montanhas do estado de Chiapas e da Selva Lacandona, no dia $1^{\circ}$ de janeiro de 1994 . O neozapatismo parece confirmar, por um lado, a posição de Touraine acerca da perversa relação que pode existir entre exercício da democracia e lógicas institucionais de participação e decisão política. Touraine afirma que quanto mais um partido político considera-se portador de um modelo de sociedade (observe-se a história dos diferentes modelos político-institucionais latino-americanos), mais se enfraquece a democracia e mais subordinados estão os cidadãos aos poderes dos dirigentes políticos. No caso do México, que se deparou com o movimento neozapatista, o Partido Revolucionário Institucional (PRI) tinha-se assentado no imaginário e na prática social dos mexicanos ao longo dos seus 70 anos no poder de um Estado que concentrava, institucionalmente (assim como em relações típicas de clientelismo político), todos os canais de demandas e reivindicações surgidas da sociedade. Que aconteceu? A aparição de um sujeito social que, profundamente visível para o México contemporâneo, persistente ao longo do tempo, fez de suas demandas por democratização e afirmação da sua identidade indígena a principal ferramenta de transformação política e cultural. O neozapatismo conseguiu transcender a lógica institucional e política do México moderno, inaugurando uma nova etapa política que se vê acompanhada pela derrota nas últimas eleições do PRI e a subida no governo federal de um partido relativamente novo, o Partido Ação Nacional (PAN).

Mas uma faceta dos indígenas neozapatistas permanece sem o devido reconhecimento. Tratase daquele aspecto que se refere à defesa de uma identidade cultural lesionada historicamente: a identidade indígena. O caráter étnico do movimento é indubitável e, assim, um novo terreno inaugurase nos conflitos e nas lutas estabelecidas. Esse terreno é o cultural, o simbólico, o que se estabelece como conseqüência de uma pluralidade cultural ocultada e negada (vide GADEA, 1999). Dessa maneira, as referências à diversidade cultural e aos processos de subjetivação, que menci- 
ona Touraine, adquirem singular centralidade. Para Touraine, o movimento neozapatista estaria definido como uma formação político-social própria de momentos posteriores à União Soviética, sem a influência do "castrismo revolucionário" e próprio do esgotamento das guerrilhas de esquerda. O movimento neozapatista tem expressado com transcendência mundial a união sui generis da defesa de uma identidade particular com um programa de democratização nacional, quer dizer, a aliança de uma luta cultural com um processo democratizador, em que, ao combinar o fato de "viver juntos” com "nossas diferenças”, renova a figura moderna da democracia, ao reconhecer o pluralismo e manter regras universais de Direito.

Chegamos assim a reconhecer um traço interessante nas contribuições de análises de Touraine para as realidades latino-americanas: a idéia de que a racionalização, acompanhada e iluminada pelas aspirações universalistas e seu correlato de suposta convivência social, deve combinar-se com a idéia da defesa do sujeito, entendida como um "desejo" que atravessa o político, o moral e o ético em indivíduos e culturas. Com isso, a tensão parece irresolúvel, constitutiva da modernidade latino-americana, segundo a qual as categorias que se manifestam nos movimentos sociais definemse cada vez menos por uma atividade ou pelo lugar que os sujeitos ocupam na estrutura de produção e cada vez mais por uma origem ou pertença cultural. Segundo Touraine, a categoria "sujeito" aparece, então, cada vez mais central e determinante para a análise dos movimentos sociais atuais.

Será, pois, a respeito da sociedade contemporânea que o sujeito assume prioridade na análise sociológica de Touraine. O próprio autor define a existência de três fases sucessivas em sua trajetória intelectual, às quais atribui centralidade a um tipo de sujeito-ator privilegiado da ação em cada momento histórico: 1. da industrialização e do movimento operário tendo a classe como ator central; 2. os movimentos sociais propriamente ditos (enquanto atores coletivos) no coração da vida societária e na historicidade; 3. a compreensão do sujeito e sua transformação em ator social.

Suas análises sobre a América Latina, e seus focos de interesses, acompanharam a vitalidade dessa trajetória intelectual. Dessa forma, na primeira fase, bastante influenciado pelo debate marxista, pesquisou a formação de uma consciência operária nos trabalhadores de carvão e de metalurgia no Chile e no operariado de São Paulo. No livro A sociedade pós-industrial, iniciou a transição para conceber os movimentos sociais para além das lutas de classe.

Assim, no segundo período, Touraine desenvolveu sua obra-mestre sobre os movimentos sociais (A produção da sociedade), dialogando tensamente com a teoria sociológica em um sentido mais amplo, especialmente com as teorias da ação e das instituições políticas, tendo como pano de fundo o debate sobre a democracia. Face à tradição sociológica, estabeleceu um espaço privilegiado de análise - o da historicidade - cuja dinâmica associa-se à ação dos movimentos sociais, que necessitam de contextos de relativa abertura democrática para desenvolverem-se. Em relação à América Latina, refletiu sobre as relações entre as raízes institucionais autoritárias (caudilhismo, clientelismo, populismo, paternalismo) e os potenciais de lutas dos atores dominados (dos comunitarismos aos movimentos históricos), o que sintetiza em uma obra maior, denominada Palavra e sangue (1989).

Será, portanto, no terceiro período, ampliando o leque de suas reflexões, incorporando debates contemporâneos da Filosofia Política e da Psicanálise, que construiu uma teoria mais abrangente sobre a liberdade do sujeito e o sujeito da ação, pessoal e coletiva. Mas, como bem diz Touraine, o sujeito não é o indivíduo (no sentido liberal do termo), pois "ser sujeito" significa ter a vontade de ser ator, isto é, atuar e modificar seu meio social mais do que ser determinado por ele. Portanto, a liberdade do sujeito será construída em sua relação com o outro, na alteridade, mas não na subjugação, não na integração sistêmica acrítica, mas na busca do reconhecimento, na sua universalidade e na sua particularidade. Por isso, os temas do multiculturalismo, do dilema entre igualdade e diferença e da educação intercultural também assumem relevância em seus debates, tendo como lastro social a condição democrática, sob a premissa de que o sujeito possa tornar-se ator em seu destino pessoal e coletivo. Conforme afirma: "Uma sociedade democrática é uma sociedade que reconhece o outro, não na sua diferença, mas como sujeito, quer dizer, de modo a unir o universal e o particular [...], uma vez que o sujeito é ao mesmo tempo universalista e comunitário e ser sujeito é estabelecer um elo entre esses dois uni- 
versos, ensaiar viver o corpo e o espírito, emoção e razão" (TOURAINE, 1994b, p. 1-2).

É nessa direção que Touraine destaca a centralidade do feminismo ${ }^{2}$ e das minorias étnicas enquanto sujeitos de transformação da historicidade contemporânea. Os movimentos de reconhecimento das minorias indígenas do México, da Guatemala, do Equador, da Bolívia e de outros países latino-americanos, são considerados pelo autor como momentos democratizantes, os quais, ao reivindicar uma especificidade cultural indígena, estão ampliando os sistemas democráticos. A democracia não será, assim, só um conjunto de instituições, mas, antes de tudo, uma luta das minorias contra o poder e a ordem estabelecida: é a luta contra sua redução à condição de mero trabalhador, de integração acrítica ao sistema.

Portanto, a democracia tem que ser pensada para além de sua institucionalidade: tem que ser pensada como uma das dimensões da constituição do sujeito em ator social - sempre se levando em conta o cenário histórico, isto é, examinando se vivemos a emergência de um novo tipo de sociedade, com a definição de novos problemas, novos conflitos, e, portanto, novos atores. Para a América Latina, a partir de uma perspectiva touraineana, podem-se destacar elementos para a análise dos movimentos dos sem-terra, dos movimentos urbanos, do movimento negro, dos jovens, do ecologismo, do feminismo e dos movimentos por uma educação intercultural, além dos movimentos indígenas, que são emblemáticos para a América Latina e que já foram mencionados anteriormente. Esses movimentos permitem-nos pensar a partir da premissa de Touraine de que o sujeito está presente em todos os lugares em que se revela a vontade de ser, ao mesmo tempo, memória e projeto, cultura e atividade (cf. TOURAINE, 1997, p. 303), e poderiam ser acrescentados: racionalidade e subjetivação, ou universo instrumental e universo simbólico. Essas duas dimensões das ações coletivas podem ser apreendidas nas diversas experiências dos movimentos sociais na América Latina.

O Movimento dos Trabalhadores Rurais Semterra (MST), no Brasil, na sua continuidade ao

2 Sobre este ponto, vide maiores detalhes em entrevista concedida a Miriam Adelman (2004). projeto da Teologia da Libertação, combina a racionalidade da luta pela terra com a simbologia da memória de lutas camponesas históricas, de reconhecimento das diversidades regionais e culturais, com o ideário da solidariedade e com a mística em suas expressões artísticas (cf. PIANA, 2001; SCHERER-WARREN, 2002).

Em relação aos contextos urbanos, os movimentos societários combinam a luta contra a exclusão e a privação de identidade com aspirações democráticas, transformando-se em movimento social quando articulam história de vida pessoal e coletiva como, por exemplo, no Movimento dos Sem-Teto. Entretanto, com apoio em Touraine, podemos compreender a intrincada ambigüidade dessas ações coletivas em relação à questão democrática, especialmente aquelas relacionadas aos temas da pobreza ou das carências nas cidades: "Não é o papel dos pobres como trabalhadores, como cidadãos ou como membros de uma comunidade que dá a este tema a importância que tem; não é o que fazem, mas o que sofrem; não é o que possuem, mas aquilo de que são privados [...]. Sua miséria, a exclusão e a repressão que eles sofrem é que dão ao seu protesto um valor fundamental. Porque é quando os problemas da vida privada e os da vida pública se unem da forma mais intensa para dar origem a um protesto cujo objetivo é a defesa da vida" (TOURAINE, 1989, p. 276).

É por isso que em movimentos como o dos sem-teto, a presença das mães e das crianças evidencia a busca de um reconhecimento na esfera pública, durante as negociações e na afirmação dos direitos fundamentais da pessoa humana. Seu interlocutor será muito mais o Estado do que uma categoria social, o que, partindo-se de Touraine, poderia vir a explicar o seu radicalismo conservador, que mistura os discursos mais extremos com o clientelismo mais utilitário.

O movimento ecológico também pode ser analisado a partir da multidimensionalidade analítica touraineana. Uma aplicação desse enfoque foi realizada por Castells (1997), com a elaboração de uma tipologia dos movimentos ambientalistas (a partir da identidade dos sujeitos-atores, da definição do adversário da luta e dos objetivos da ação - projeto-utopia). O autor conclui que, especialmente na América Latina, grupos ecologistas estão articulando-se com grupos de direitos humanos, de mulheres, organizações não-governamen- 
tais, formando uma coalizão que não ignora a política institucional mas vai além dela. Dessa forma, conectam movimentos de base com mobilizações simbólicas em nome de uma justiça ambiental, ou seja, Realpolitik e utopia, cepticismo e esperança (idem, p. 133); em outras palavras, razão instrumental e razão simbólica.

No campo dos movimentos identitários, o feminismo, os movimentos étnicos e os movimentos jovens assumem relevância na esfera pública, na contemporaneidade latino-americana. Para o movimento feminista, pode-se destacar sua capacidade de associar vida profissional (racionalidade) e vida afetiva (subjetivação), com o desejo e a luta para ampliar a sua participação na esfera pública, ampliando a democracia ${ }^{3}$.

Quanto à etnicidade, para Touraine não há democracia sem o reconhecimento da diversidade entre as culturas e da dominação que existe entre elas. O sujeito deve combinar instrumentalidade e identidade. Dessa forma, pode-se observar que, no Brasil, o movimento negro vem combinando lutas pela ação afirmativa, na esfera das políticas sociais, com as lutas contra a discriminação racial e o reconhecimento de suas raízes históricas e especificidades culturais.

Os movimentos jovens emergentes, tais como o hip hop, por meio de práticas político-culturais artísticas, constituem-se em sujeitos-atores de resistência no plano das desigualdades econômicas e das discriminações culturais. Nas palavras de Weller (2002, p. 1), "ao mesmo tempo em que os jovens negros em São Paulo (grupos de rap) estão fortemente constituídos em torno de práticas culturais e de lazer, convertem-se por outro lado em redes de articulação das experiências cotidianas, elaborando orientações coletivas de vida e formas de enfrentar as diferentes experiências de marginalização e discriminação”.

Esses movimentos acabam, muitas vezes, associando um movimento cultural a um novo mo-

\footnotetext{
3 Sobre a difícil luta dos sujeitos feministas face à tradição estatal autoritária brasileira, vide Alvarez (1990).
}

vimento societário (cf. TOURAINE, 1997, cap. III), isto é, associando um chamamento moral a um conflito diretamente social, que opõe um ator a outro, a um adversário, que pode vir a ser definido a partir de um tipo de orientação "classista" (cf. WELLER, 2002, p. 11-18).

Por fim, em relação às experiências de educação intercultural, poderíamos perguntar com Touraine: como combinar a liberdade do sujeito pessoal com o reconhecimento das diferenças culturais e as garantias institucionais que protegem essas liberdades e essas diferenças? Para o autor, a Escola do Sujeito (TOURAINE, 1997, cap. VIII) deve visar a compreender o outro em sua cultura, isto é, em seu esforço por ligar identidade e instrumentalidade, ou seja, racionalidade e subjetivação. Denise Cogo, em pesquisa sobre espaços educacionais interculturais, segue essa orientação: "Busco compreender [...] as dinâmicas identitárias que colocam em relação alunos e professores a partir de suas múltiplas posições identitárias de classe, de etnia, de gênero, de idade, de origem, de imigração, de trabalho, do nacional, do regional etc. Posições que concorrem para a constituição de complexos cenários de multiculturalidade nesses espaços, permitindo culminar com a reflexão sobre as possibilidades da comunicação intercultural nos espaços educativos pesquisados em termos de uma Escola do Sujeito como aquela concebida por Alain Touraine para definir relações educativas que se movem pelo desejo de corrigir as desigualdades de situações e oportunidades, a formação e a reafirmação do Sujeito pessoal e a importância atribuída à diversidade histórica e cultural dos Sujeitos educativos" (COGO, 2000, p. 18; grifos no original).

Podemos concluir que a Sociologia de Touraine - na constante busca explicativa das interfaces e tensões entre modernização versus desmodernização; universo instrumental versus universo simbólico; racionalização versus subjetivação; dominação-subjugação dos indivíduos versus liberdade do sujeito; enfim, totalitarismo versus democracia - apresenta-se como um referencial relevante para analisar-se os dilemas da modernidade e da democratização em cenários latino-americanos contemporâneos. 
Carlos A. Gadea (cgadea@unisinos.br) é Doutor em Sociologia Política pela Universidade Federal de Santa Catarina (UFSC) e Professor do Programa de Pós-graduação em Ciências Sociais da Universidade do Vale do Rio dos Sinos (Unisinos).

Ilse Scherer Warren (ilse@manezinho.com.br) é Doutora em Sociologia pela Universidade de Paris X (Nanterre) e Professora do Programa de Pós-graduação em Sociologia Política da Universidade Federal de Santa Catarina (UFSC).

\section{REFERÊNCIAS BIBLIOGRÁFICAS}

ADELMAN, M. 2004. Sexo, gênero, sujeito : uma entrevista com Alain Touraine. Revista de Sociologia e Política, Curitiba, n. 23, p. 169174, nov.

ALVAREZ, S. E. 1990. Engendering Democracy in Brazil - Women's Movements in Transition Politics. New Jersey : Princeton University.

CASTELLS, M. 1997. The Information Age : Economy, Society and Culture. V. II : The Power of Identity. Oxford : Blackwell.

COGO, D. M. 2000. Multiculturalismo, comunicação e educação. Possibilidades da comunicação intercultural em espaços educacionais. São Paulo. Tese (Doutorado em Educação). Universidade de São Paulo.

GADEA, C. A. 1999. O ideal comunitário como resistência à modernidade-global. Um estudo sobre o Movimento Neo-zapatista de Chiapas. Florianópolis. Dissertação (Mestrado em Sociologia Política). Universidade Federal de Santa Catarina.

2004. Acciones coletivas y modernidad global : el movimiento neozapatista. Toluca : Universidad Autónoma del Estado de México.

GADEA, C. A. \& SCHERER-WARREN, I. 2005. Alain Touraine e a democracia na América Latina. Cadernos do CEAS, Salvador, n. 220, p. 9-18, nov.-dez.

PIANA, M. 2001. A música movimento : estratégias e significados da produção musical do MST. Florianópolis. Dissertação (Mestrado em Sociologia Política). Universidade Federal de Santa Catarina.

SCHERER-WARREN, I. 2002. A atualidade dos movimentos sociais rurais na nova ordem mundial. In : SCHERER-WARREN, I. \& FERREIRA, J. M. C. (orgs.). Transformações sociais e dilemas da globalização - um diálogo Brasil/Portugal. São Paulo : Cortez.

TOURAINE, A. 1973a. La société postindustrielle. Paris : Denoël.

. 1973b. Production de la société. Paris : Seuil.

1989. Palavra e sangue : política e sociedade na América Latina. São Paulo : Unicamp.

1994a. Crítica da modernidade. Petrópolis : Vozes.

. 1994b. Rencontre avec Alain Touraine. Entretien avec Jean-François Dortier et Patrick Maret. Mensuel, n. 42, août. Disponível em : http://www.ac-corse.fr/disciplines/ scienceseco/Atour1.html. Data de acesso : 25.maio.2006.

1997. ¿Podremos vivir juntos? Iguales y diferentes. Buenos Aires : Fondo de Cultura Económica.

WELLER, W. 2002. Orientações coletivas e a construção da identidade negra em grupos juvenis na periferia de São Paulo. Artigo apresentado no VI Encontro Nacional de História Oral, realizado na Universidade de São Paulo, de 28 de abril e $1^{\circ}$ de maio. Digit. 